\title{
An Endohedral Single-Molecule Magnet with Long Relaxation Times: $\mathrm{DySc}_{2} \mathrm{~N} @ \mathrm{C}_{80}$
}

Rasmus Westerström, ${ }^{\dagger \dagger}$ Jan Dreiser, ${ }^{\ddagger}$ Cinthia Piamonteze, ${ }^{\ddagger}$ Matthias Muntwiler, ${ }^{\ddagger}$ Stephen Weyeneth, ${ }^{\dagger}$ Harald Brune, ${ }^{\text {II }}$ Stefano Rusponi, ${ }^{\text {II }}$ Frithjof Nolting, ${ }^{\ddagger}$ Alexey Popov, ${ }^{\S}$ Shangfeng Yang, ${ }^{\S}, \|$ Lothar Dunsch, ${ }^{\S}$ and Thomas Greber* ${ }^{\dagger}$

${ }^{\dagger}$ Physik-Institut, Universität Zürich, Winterthurerstrasse 190, CH-8057 Zürich, Switzerland

${ }^{\ddagger}$ Swiss Light Source, Paul Scherrer Institut, CH-5232 Villigen PSI, Switzerland

II Institute of Condensed Matter Physics, Ecole Polytechnique Fédérale de Lausanne, CH-1015 Lausanne, Switzerland

${ }^{\S}$ Department of Electrochemistry and Conducting Polymers, Leibniz Institute of Solid State and Materials Research, Dresden, D-01069 Dresden, Germany

"Hefei National Laboratory for Physical Sciences at Microscale, Department of Materials Science and Engineering, University of Science and Technology of China, 96 Jinzhai Road, Hefei 230026, China

Supporting Information

ABSTRACT: The magnetism of $\mathrm{DySc}_{2} \mathrm{~N} @ \mathrm{C}_{80}$ endofullerene was studied with $\mathrm{X}$-ray magnetic circular dichroism (XMCD) and a magnetometer with a superconducting quantum interference device (SQUID) down to temperatures of $2 \mathrm{~K}$ and in fields up to $7 \mathrm{~T}$. XMCD shows hysteresis of the $4 \mathrm{f}$ spin and orbital moment in Dy ${ }^{\mathrm{III}}$ ions. SQUID magnetometry indicates hysteresis below $6 \mathrm{~K}$, while thermal and nonthermal relaxation is observed. Dilution of DySc ${ }_{2} \mathrm{~N} @ \mathrm{C}_{80}$ samples with $\mathrm{C}_{60}$ increases the zero-field $4 \mathrm{f}$ electron relaxation time at $2 \mathrm{~K}$ to several hours.

Tncorporation of magnetic ions in molecular clusters can lead 1 to the formation of so-called single-molecule magnets (SMMs). ${ }^{1}$ These molecules are characterized by slow magnetic relaxation, making them candidates for applications in quantum computing, spintronics, and high-density storage devices. ${ }^{2}$

Double-decker phthalocyanines $\left[\mathrm{Pc}_{2} \mathrm{Ln}^{\mathrm{III}}\right]^{-}\left(\mathrm{Ln}^{\mathrm{III}}=\mathrm{Tb}\right)^{3 \mathrm{a}, \mathrm{b}}$ $\mathrm{Dy},{ }^{3 \mathrm{a}, \mathrm{b}}$ or $\left.\mathrm{Ho}^{3 \mathrm{c}}\right)$ were the first mononuclear complexes shown to exhibit SMM behavior. The class of mononuclear SMMs has since been extended by mononuclear complexes of lanthani$\operatorname{des}^{4 a-j}$, actinides ${ }^{5 a-c}$ and first-row transition metals. ${ }^{5 \mathrm{~d}, \mathrm{e}}$ Dinuclear dysprosium complexes have also been reported to show SMM behavior. ${ }^{6 a-d}$ In this Communication we show that the mononuclear dysprosium cluster $\mathrm{DySc}_{2} \mathrm{~N} @ \mathrm{C}_{80}$ ehibits exceptionally long relaxation times.

Magnetism in lanthanide complexes is somewhat different from their transition-metal counterparts. The $4 \mathrm{f}$ levels of lanthanide ions have an unquenched orbital moment and a $(2 J$ +1 )-fold degenerate ground state. If this degeneracy is lifted in a ligand field (LF), different $J_{z}$ states can be separated by an energy comparable to the thermal energy at room temperature. 4

Metal nitride cluster fullerenes (NCFs) offer the opportunity to encage up to three paramagnetic ions. Since their first isolation, ${ }^{7 \mathrm{a}}$ they have received widespread interest in research. $^{7 \mathrm{~b}-\mathrm{d}}$ Varying the three metal ions implies a great diversity of endohedral units: $\mathrm{M}_{x} \mathrm{Sc}_{3-x} \mathrm{~N} @ \mathrm{C}_{80}(x=1,2 ; \mathrm{M}=$ $\left.\mathrm{Er},{ }^{8 \mathrm{a}, \mathrm{b}} \mathrm{Gd}^{8 \mathrm{c}, \mathrm{d}} \mathrm{Y},{ }^{8 \mathrm{e}} \mathrm{Lu}^{8 \mathrm{f}}\right), \mathrm{TbSc}_{2} \mathrm{~N} @ \mathrm{C}_{80}{ }^{8 \mathrm{~g}} \mathrm{CeSc}_{2} \mathrm{~N} @ \mathrm{C}_{80}{ }^{8 \mathrm{~h}}$ $\mathrm{Lu}_{2} \mathrm{CeN} @ \mathrm{C}_{80}, \mathrm{NdSc}_{2} \mathrm{~N} @ \mathrm{C}_{80},{ }^{8 \mathrm{f}} \mathrm{DySc}_{2} \mathrm{~N} @ \mathrm{C}_{76},{ }^{8 \mathrm{i}} \mathrm{DySc}_{2} \mathrm{~N} @$

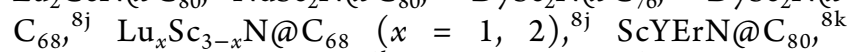
$\mathrm{Lu}_{x} \mathrm{Y}_{3-x} \mathrm{~N} @ \mathrm{C}_{80}(x=1,2),{ }^{81}$ and $\mathrm{TiSc}_{2} \mathrm{~N} @ \mathrm{C}_{80}{ }^{8 \mathrm{~m}}$

Investigations on the magnetism of single ions inside fullerenes started with $\mathrm{Gd} @ \mathrm{C}_{82}$, which turned out to be paramagnetic down to $3 \mathrm{~K}^{9 \mathrm{a}}$ For Dy@ $\mathrm{C}_{82}$, superconducting quantum interference device (SQUID) and X-ray magnetic circular dichroism (XMCD) measurements revealed paramagnetic behavior down to $1.8 \mathrm{~K}^{9 \mathrm{~b}-\mathrm{e}}$ The observed magnetic moment is reduced in this system compared to the free trivalent Dy ion, which is attributed to a quenched orbital moment due to the crystal field splitting from the carbon cage and/or electron back-donation from the cage to the Dy ion. $9 \mathrm{c}$ In contrast, $\mathrm{C}_{80} \mathrm{NCF}$ have a carbon cage with a closed shell, and less coupling between the moments of the metal ions and a diamagnetic cage is expected. SQUID magnetization measurements on $\mathrm{Ln}_{3} \mathrm{~N} @ \mathrm{C}_{80}(\mathrm{Ln}=\mathrm{Tb} \text { and } \mathrm{Ho})^{10 \mathrm{a}, \mathrm{b}}$ are in line with a model where the $\mathrm{LF}$ of the $\mathrm{N}^{3-}$ ion induces an easy axis for the individual $\mathrm{Ln}^{\mathrm{III}}$ moments directed along the respective $\mathrm{Ln}-\mathrm{N}$ bond. In this model the magnetic anisotropy due to the LF is strong enough that the $\mathrm{Ln}^{\text {III }}$ moments do not align with the external field but instead parallel to the bond directions. ${ }^{10 a}$ Nevertheless, the magnetization curves recorded on $\mathrm{Ln}_{3} \mathrm{~N} @ \mathrm{C}_{80}$ $\left(\mathrm{Ln}=\mathrm{Tb},{ }^{10 \mathrm{a}, \mathrm{b}} \mathrm{Ho},{ }^{10 \mathrm{a}, \mathrm{b}} \mathrm{Tm},{ }^{10 \mathrm{c}} \mathrm{Er}^{10 \mathrm{~d}, \mathrm{e}} \mathrm{Gd}^{10 f}\right)$ and $\mathrm{Er}_{x} \mathrm{Sc}_{3-x} \mathrm{~N} @$ $\mathrm{C}_{80}{ }^{10 \mathrm{~d}}(x=1,2)$ above $1.8 \mathrm{~K}$ showed paramagnetism without hysteresis.

In the present case we have a single $\mathrm{Dy}^{\mathrm{III}}$ ion in a diamagnetic carbon cage (see Figure 1). Since $\mathrm{Sc}^{\mathrm{III}}$ ions are not paramagnetic, the LF due to the $\mathrm{N}^{3-}$ ion will result in magnetic anisotropy directed along the $\mathrm{Dy}-\mathrm{N}$ bond. Furthermore, if the LF stabilizes a ground state with a large $J_{z}$, the prerequisite for magnetic bistability is fulfilled.

Received: February 1, 2012

Published: May 14, 2012 


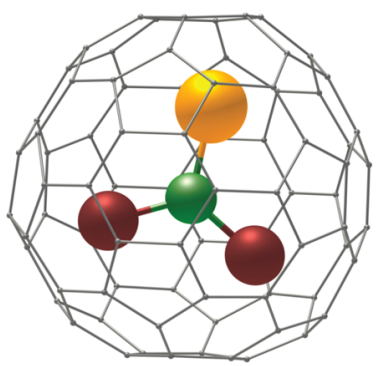

Figure 1. Chemical structure of $\mathrm{DySc}_{2} \mathrm{~N} @ \mathrm{C}_{80}$ (green, $\mathrm{N}$; purple, Sc; orange, Dy). The $\mathrm{C}_{80}$ cage is shown as a wire frame.

The robustness of endofullerene molecules and their ordering on surfaces ${ }^{11}$ makes them ideal models for studying and possibly exploiting the intrinsic magnetic properties of SMMs deposited on substrates. Here we show that $\mathrm{DySc}_{2} \mathrm{~N} @$ $\mathrm{C}_{80}$ exhibits $\mathrm{SMM}$ behavior with long relaxation times. By combining element-specific $\mathrm{XMCD}^{12}$ and SQUID magnetometry on diluted and nondiluted samples, it is demonstrated that the magnetic behavior of $\mathrm{DySc}_{2} \mathrm{~N} @ \mathrm{C}_{80}$ can be attributed to single Dy ${ }^{\text {III }}$ ions.

The synthesis, $\mathrm{XMCD}^{13}$ and SQUID measurement details are decribed in the Supporting Information. The SQUID measurements were performed using undiluted samples (1) and a sample diluted with $\mathrm{C}_{60}(2)$.

Figure 2a displays $\mathrm{X}$-ray absorption in the energy range of the Dy $\mathrm{M}_{4,5}$-edges, with data normalized to the maximum $3 \mathrm{~d} \rightarrow$ 4f absorption signal of right and left circular polarized light $\left(I^{+}+I^{-}\right)$. Spectra were recorded on 1 at $2 \mathrm{~K}$ and $6 \mathrm{~T}$. Polarization-dependent X-ray absorption spectra after background subtraction, $I^{+}$and $I^{-}$, and the resulting XMCD spectrum, $I^{+}-I^{-}$, are shown in the middle and bottom of Figure $2 \mathrm{a}$. Using sum rules, ${ }^{14 \mathrm{a}, \mathrm{b}}$ the average magnetic moment of the Dy ${ }^{\text {III }}$ ions was extracted from the dichroism and the total absorption spectra in Figure 2a. From the calculation we obtain $\left\langle L_{z}\right\rangle /\left\langle S_{z}\right\rangle=1.75$, in close agreement with the value of 2 derived from a $4 \mathrm{f}^{9}$ occupancy and Hund's rules, which predict a ${ }^{6} H_{15 / 2}$ ground state. The expectation value of the Dy $\left\langle T_{z}\right\rangle$ operator was evaluated according to eq 8 in ref $14 \mathrm{~b}$. At saturation, the average $\mathrm{Dy}{ }^{\mathrm{III}}$ magnetic moment is $m_{\text {sat }}=4.4 \mu_{\mathrm{B}}$. This value is lower than $(15 / 2) g_{\mathrm{J}} \mu_{\mathrm{B}}=10 \mu_{\mathrm{B}}$ expected from the Hund ground state with a Landé factor $g_{\mathrm{J}}=20 / 15$, even if it is reduced by a factor of $1 / 2$ due to an isotropic distribution of the easy axes. ${ }^{14 c}$ In the present case, the LF could stabilize a ground state different from $J_{z}= \pm 15 / 2$, explaining the additional reduction of the observed magnetic moment.

Figure $2 \mathrm{~b}$ displays the element-specific magnetization curve obtained from XMCD at the Dy $\mathrm{M}_{5}$-edge, together with the field dependence of the total magnetic moment measured by SQUID magnetometry. The agreement between the two data sets demonstrates that the magnetic moments measured by our SQUID magnetometer can be attributed to the Dy ${ }^{\mathrm{III}}$ ions. From the observed hysteresis loops it is evident that the system exhibits slow magnetic relaxation. The shape of the hysteresis depends on the relaxation rate, so the deviation between the two data sets may be caused by a slightly higher sample temperature during XMCD measurement and different field scan rates for the two experiments, 1.3 (SQUID) and $17 \mathrm{mT}$ $\mathrm{s}^{-1}$ (XMCD).

Magnetization loops from 1 at different temperatures using SQUID magnetometry are shown in Figure 3. Below $6 \mathrm{~K}$ hysteresis is observed. Hysteresis was also detected in the range
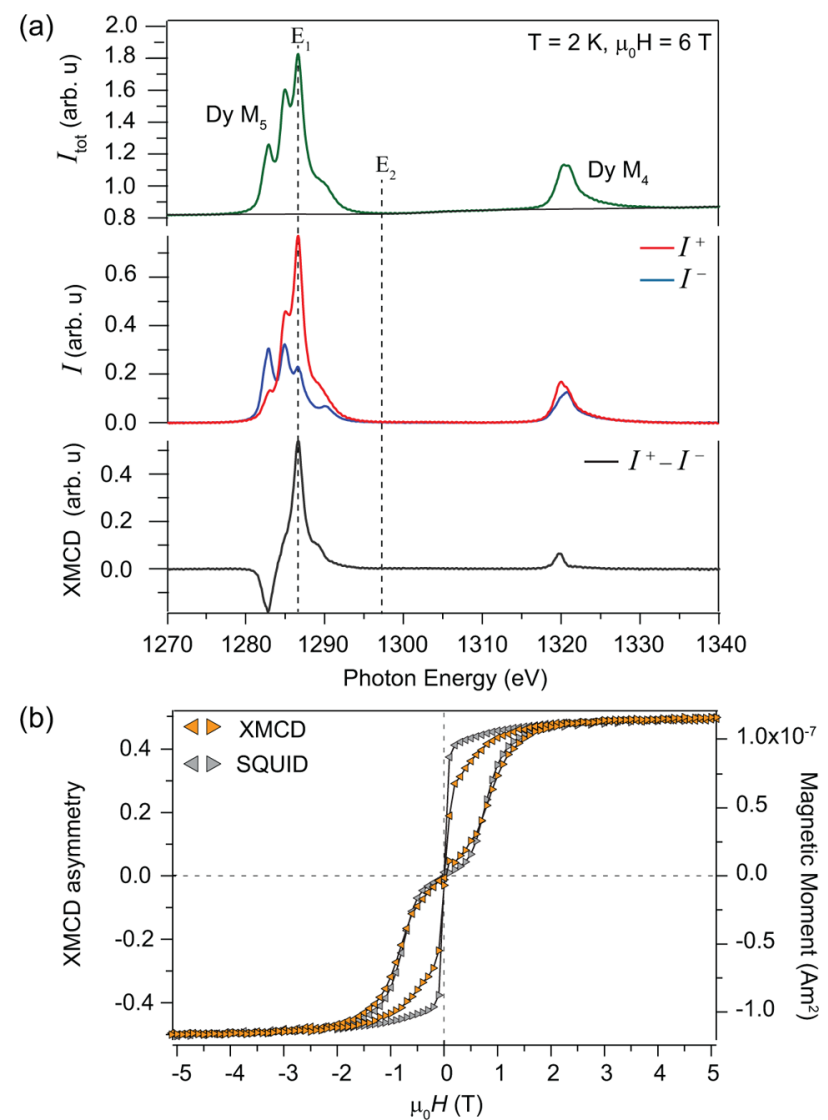

Figure 2. Results for sample 1. (a) Top: Sum of X-ray absorption spectra of both X-ray helicities, $I_{\text {tot }}$ recorded at the Dy $\mathrm{M}_{4,5}$-edge at 6 T. Middle: Polarization-dependent X-ray absorption spectra after subtraction of the background, $I^{+}$(red) and $I^{-}$(blue). Bottom: XMCD spectrum, $I^{+}-I^{-}$. (b) Magnetization curves recorded by XMCD and SQUID magnetometry at $2 \mathrm{~K}$. The element-specific magnetization curve was constructed from the assymmetry $\left[\left(I_{E_{1}}^{+}-I_{E_{2}}^{+}\right)-\left(I_{E_{1}}^{-}-I_{E_{2}}^{-}\right)\right] /$ $\left[\left(I_{E_{1}}^{+}-I_{E_{2}}^{+}\right)+\left(I_{E_{1}}^{-}-I_{E_{2}}^{-}\right)\right]$where $E_{1}$ and $E_{2}$ are the photon energies in panel (a).

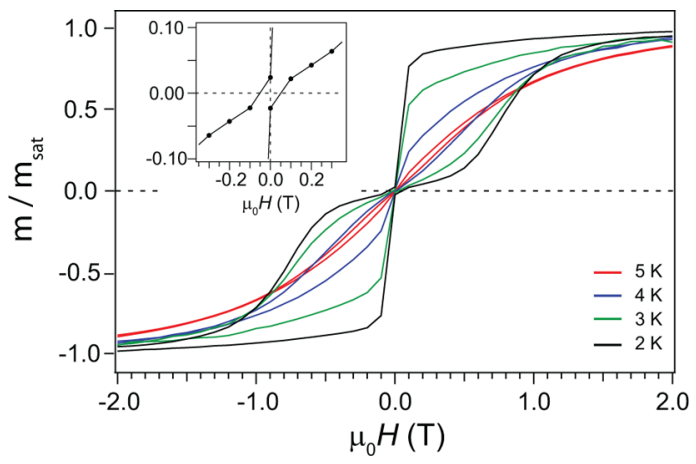

Figure 3. Temperature-dependent magnetization curves for $\mathbf{1}$ recorded using SQUID magnetometry. Inset: enlargement of the $2 \mathrm{~K}$ signal at small fields. $m_{\text {sat }}$ is the saturated magnetization at $7 \mathrm{~T}$.

$2 \leq T<5 \mathrm{~K}$ for sample 2 diluted with $10-20$ times $\mathrm{C}_{60}$, indicating that magnetic bistability is a property of single $\mathrm{Dy}{ }^{\mathrm{III}}$ ions rather than due to intermolecular magnetic interactions.

Hysteresis curves with sharp drops at low fields have been reported for other SMMs such as $\left[\mathrm{Pc}_{2} \mathrm{Dy}\right]^{-15}$ or $\left(\mathrm{Cp}^{*}\right) \mathrm{Er}$ (COT). ${ }^{4 \mathrm{f}}$ They depend not only on temperature but also on scan time, which indicates that we deal here with slow 
magnetization dynamics rather than hysteresis of a ferromagnet: The magnetization relaxes to an equilibrium that depends on field and temperature. This was further investigated by timedependent SQUID measurements. Figure $4 a$ shows three
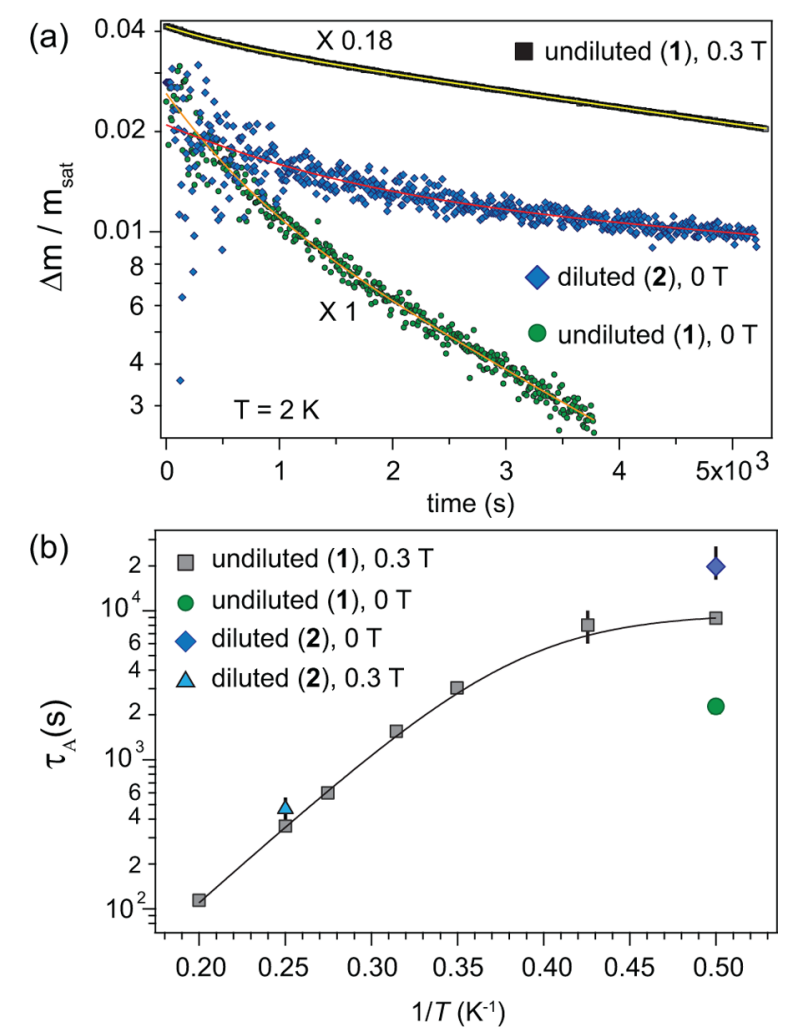

Figure 4. (a) Relaxation of the magnetization for sample $\mathbf{1}$ and $\mathbf{2}$ at $T=2 \mathrm{~K}$, with $\Delta m(t)=m(t)-m(t \rightarrow \infty) \cdot m_{\text {sat }}$ is the saturation magnetization. The lines correspond to the best fit of doubleexponential eq 1. (b) Magnetic relaxation times $\tau_{\mathrm{A}}$ as a function of inverse temperature. Decay times at $0.3 \mathrm{~T}$ for the undiluted sample were fitted to eq 2 (solid line).

relaxation curves at $2 \mathrm{~K}$. At $t=0$ the field was switched from 0.4 to $0.3 \mathrm{~T}(0.5$ to $0 \mathrm{~T})$, after being ramped down from $7 \mathrm{~T}$ at an average speed of $5.4 \mathrm{mT} \mathrm{s}^{-1}\left(4.5 \mathrm{mT} \mathrm{s}^{-1}\right)$. Below $3.5 \mathrm{~K}$ relaxation data do not exhibit a single-exponential decay, indicating more than one relaxation process. In this temperature range, a double exponential,

$$
m(t)=m(t \rightarrow \infty)+\alpha \exp \left(-t / \tau_{\mathrm{A}}\right)+\beta \exp \left(-t / \tau_{\mathrm{B}}\right)
$$

was fitted to magnetization curves $m(t)$, where data were weighted with the noise. $\alpha$ and $\beta$ are the magnetization of relaxation processes $\mathrm{A}$ and $\mathrm{B}$ at $t=0$, and $\tau_{\mathrm{A}}$ and $\tau_{\mathrm{B}}$ the corresponding relaxation times $\left(\tau_{\mathrm{A}}>\tau_{\mathrm{B}}\right)$. Above $3.5 \mathrm{~K}$, a single exponential, $\alpha \exp \left(-t / \tau_{\mathrm{A}}\right)$, was used to fit the $m(t)$ curves.

The resulting decay times for the slower process, $\tau_{\mathrm{A}}$ are displayed as a function of inverse temperature in Figure $4 \mathrm{~b}$. As expected for a thermally activated process, the relaxation times decrease with temperature.

Thermal relaxation mechanisms are generally attributed to higher order phonon processes, such as the Orbach process between the $J_{z}$ levels. To estimate the effective barrier for thermally driven relaxation, $\Delta_{\text {eff }}$ the function

$$
\tau(T)=\frac{\tau_{c} \tau_{0} \exp \left(\Delta_{\text {eff }} / k_{\mathrm{B}} T\right)}{\tau_{\mathrm{c}}+\tau_{0} \exp \left(\Delta_{\mathrm{eff}} / k_{\mathrm{B}} T\right)}
$$

was fitted to the relaxation times. $\tau_{\mathrm{c}}$ is the temperatureindependent decay time and $\tau_{0}$ the exponential prefactor for the temperature-dependent part. For 1 at $0.3 \mathrm{~T}$ we obtain $\Delta_{\text {eff }} / k_{\mathrm{B}}=$ $24 \pm 0.5 \mathrm{~K}$, which compares to $44 \mathrm{~K}$ of $\left[\mathrm{Pc}_{2} \mathrm{Dy}\right]^{-}$(at $350 \mu \mathrm{T}$ ac field). ${ }^{3 \mathrm{~b}}$ On the other hand, the exponential prefactor has an exceptionally large value, $\tau_{0}=1 \pm 0.1 \mathrm{~s}$, more than 4 orders of magnitude larger than that of $\left[\mathrm{Pc}_{2} \mathrm{Dy}\right]^{-3 \mathrm{~b}}$ This indicates peculiar magnetization dynamics in the present system. In contrast to molecules such as $\left[\mathrm{Pc}_{2} \mathrm{Dy}\right]^{-}$, magnetic moments in the $\mathrm{DySc}_{2} \mathrm{~N} @ \mathrm{C}_{80}$ endofullerene are protected by a diamagnetic cage, and low phonon density may inhibit thermal relaxation.

The temperature-independent decay times $\tau_{\mathrm{c}}^{\mathrm{A}}$ and $\tau_{\mathrm{c}}^{\mathrm{B}}$, ascribed to magnetization decay through quantum tunneling between the $\pm J_{z}$ states, are $\sim 10^{4}$ and $\sim 8 \times 10^{2}$ s, respectively. Since the Dy ${ }^{\mathrm{III}}$ ion contains an odd number of electrons, all states have double degeneracy according to Kramer's theorem, so quantum tunneling is only possible in the presence of a perturbation that lifts the degeneracy and allows the doublets to mix. In the present system, Zeeman splitting or intermolecular dipole-dipole or hyperfine interactions with the nuclear spin may give rise to such a perturbation.

The relaxation time in zero field is of particular interest since it is the "remanence time" for a given sample. In zero field there is no Zeeman splitting, and intermolecular dipole-dipole interactions, which must be small due to protection of Dy by the $\mathrm{C}_{80}$ cage, can be further weakened by increasing the distance between the Dy atoms. This was achieved by diluting the sample with $\mathrm{C}_{60}$. The data points for 2 in Figure 4 show that dilution leads to a significant increase of the relaxation time at $0 \mathrm{~T}$ and $2 \mathrm{~K}$. The relaxation time for 2 in zero field is now $>5 \mathrm{~h}$, about 9 times longer than for undiluted samples $(\sim 40$ $\min )$. The ratios $\tau_{\mathrm{B}} / \tau_{\mathrm{A}} \approx 0.2$ and $\alpha / \beta \approx 1$ for both 1 and 2 . If relaxation processes $A$ and $B$ are affected equally by intermolecular dipole-dipole interactions, this could hint that the difference between $\mathrm{A}$ and $\mathrm{B}$ is due to different Dy isotopes, i.e., hyperfine interactions between the $J_{z}$ level and the corresponding nuclear spin.

At $4 \mathrm{~K}$ and $0.3 \mathrm{~T}, 1$ and 2 exhibit the same relaxation times (within 10\%), as expected for thermally driven magnetic relaxation of individual molecules.

In summary, $\mathrm{DySc}_{2} \mathrm{~N} @ \mathrm{C}_{80}$ has been shown to be a mononuclear single-molecule magnet with hysteresis below $6 \mathrm{~K}$. The magnetic moment is attributed to the Dy ${ }^{\mathrm{III}}$ ion in the diamagnetic carbon cage, and the $4 \mathrm{f}$ electrons display exceptionally long relaxation times. If the sample is diluted, relaxation of the magnetization at $2 \mathrm{~K}$ increases by a factor of 9 .

\section{ASSOCIATED CONTENT}

\section{Supporting Information}

Full author list of ref 14c. Synthesis and details on the measurements. This material is available free of charge via the Internet at http://pubs.acs.org.

\section{AUTHOR INFORMATION}

\section{Corresponding Author}

greber@physik.uzh.ch

\section{Notes}

The authors declare no competing financial interest. 


\section{ACKNOWLEDGMENTS}

Fruitful discussions with René Monnier and Werner Urland and skillful technical assistance by Kurt Bösiger, are gratefully acknowledged. The X-ray absorption experiments were performed at the X-Treme beamline at the Swiss Light Source, Paul Scherrer Institut, Villigen, Switzerland. The project is supported by the Deutsche Forschungsgemeinschaft (DFG project PO 1602/1-1) and the Swiss National Science Foundation (SNF project 200021 129861).

\section{REFERENCES}

(1) (a) Caneschi, A.; Gatteschi, R.; Sessoli, D.; Barra, A. L.; Brunel, L.; Guillot, M. J. J. Am. Chem. Soc. 1991, 113, 5873. (b) Sessoli, R.; Tsai, H.-L.; Schake, A. R.; Wang, S.; Vincent, J. B.; Folting, K.; Gatteschi, D.; Christou, G.; Hendrickson, D. N. J. Am. Chem. Soc. 1993, 115, 1804. (c) Sessoli, R.; Gatteschi, D.; Caneschi, A.; Novak, M. Nature 1993, 365, 141. (d) Friedman, J. R.; Sarachik, M. P.; Tejada, J.; Ziolo, R. Phys. Rev. Lett. 1996, 76, 3830. (e) Christou, G.; Gatteschi, D.; Hendrickson, D. N.; Sessoli, R. MRS Bull. 2000, 25, 66. (f) Cadiou, C.; Murrie, M.; Paulsen, C.; Villar, V.; Wernsdorfer, W.; Winpenny, R. E. P. Chem. Commun 2001, 2666.

(2) (a) Leuenberger, M. N.; Loss, D. Nature 2001, 410, 789. (b) Bogani, L.; Wernsdorfer, W. Nat. Mater. 2008, 7, 179.

(3) (a) Ishikawa, N.; Sugita, M.; Ishikawa, T.; Koshihara, S.-y.; Kaizu, Y. J. Am. Chem. Soc. 2003, 125, 8694. (b) Ishikawa, N.; Sugita, M.; Ishikawa, T.; Koshihara, S.-y.; Kaizu, Y. J. Phys. Chem. B 2004, 108, 11265. (c) Ishikawa, N.; Sugita, M.; Wernsdorfer, W. J. Am. Chem. Soc. 2005, 127, 3650.

(4) (a) AlDamen, M. A.; Clemente-Juan, J. M.; Coronado, E.; MartíGastaldo, C.; Gaita-Ariño, A. J. Am. Chem. Soc. 2008, 130, 8874. (b) AlDamen, M. A.; Cardona-Serra, S.; Clemente-Juan, J. M.; Coronado, E.; Gaita-Ariño, A.; Martí-Gastaldo, C.; Luis, F.; Montero, O. Inorg. Chem. 2009, 48, 3467. (c) Li, D.-P.; Wang, T.-W.; Li, C.-H.; Liu, D.-S.; Li, Y.-Z.; You, X.-Z. Chem. Commun. 2010, 46, 2929. (d) Jiang, S.-D.; Wang, B.-W.; Su, G.; Wang, Z.-M.; Gao, S. Angew. Chem., Int. Ed. 2010, 49, 7448. (e) Gonidec, M.; Luis, F.; Vilchez, A.; Esquena, J.; Amabilino, D.; Veciana, J. A. Angew. Chem. 2010, 122, 1667. (f) Jiang, S.-D.; Wang, B.-W.; Sun, H.-L.; Wang, Z.-M.; Gao, S. J. Am. Chem. Soc. 2011, 133, 4730. (g) Watanabe, A.; Yamashita, A.; Nakano, M.; Yamamura, T.; Kajiwara, T. Chem.-Eur. J. 2011, 17, 7428. (h) Car, P.-E.; Perfetti, M.; Mannini, M.; Favre, A.; Caneschi, A.; Sessoli, R. J. Am. Chem. Soc. 2011, 47, 3751. (I) Jeletic, M.; Lin, P.-H.; J. Le Roy, J.; Korobkovand, I.; Gorelsky, S. I.; Murugesu, M. J. Am. Chem. Soc. 2011, 133, 19286. (j) Jiang, S.-D.; Liu, S.-S.; Zhou, L.-N.; Wang, B.-W.; Wang, Z.-M.; Gao, S. Inorg. Chem. 2012, 51, 3079.

(5) (a) Rinehart, J. D.; Long, J. R. J. Am. Chem. Soc. 2009, 131, 12558. (b) Antunes, M. A.; Pereira, L. C. J.; Santos, I. C.; Mazzanti, M.; Marc-alo, J.; Almeida, M. Inorg. Chem. 2011, 50, 9915. (c) Magnani, N.; Apostolidis, C.; Morgenstern, A.; Colineau, E.; Griveau, J.-C.; Bolvin, H.; Walter, O.; Caciuffo, R. Angew. Chem., Int. Ed. 2011, 50, 1696. (d) Freedman, D. E.; Harman, W. H.; Harris, T. D.; Long, G. J.; Chang, C. J.; Long, J. R. J. Am. Chem. Soc. 2010, 132, 1224. (e) Zadrozny, J. M.; Long, J. R. J. Am. Chem. Soc. 2011, 133, 20732.

(6) (a) Long, J.; Habib, F.; Lin, P.-H.; Korobkov, I.; Enright, G.; Ungur, L.; Wernsdorfer, W.; Chibotaru, L. F.; Murugesu, M. J. Am. Chem. Soc. 2011, 133, 5319. (b) Habib, F.; Lin, P.-H.; Long, J.; Korobkov, I.; Wernsdorfer, W.; Murugesu, M. J. Am. Chem. Soc. 2011, 133, 8830. (c) Guo, Y.-N.; Xu, G.-F.; Wernsdorfer, W.; Ungur, L.; Guo, Y.; Tang, J.; Zhang, H.-J.; Chibotaru, L. F.; Powell, A. K. J. Am. Chem. Soc. 2011, 133, 11948. (d) Lin, P.-H.; Sun, W.-B.; Yu, M.-F.; Li, G.-M.; Yan, P.-F.; Murugesu, M. J. Am. Chem. Soc. 2011, 47, 10993.

(7) (a) Stevenson, S.; Rice, G.; Glass, T.; Harich, K.; Cromer, F.; Jordan, M.; Craft, J.; Hadju, E.; Bible, R.; Olmstead, M.; Maitra, K.; Fisher, A.; Balch, A.; Dorn, H. Nature 1999, 401, 55. (b) Dunsch, L.; Yang, S. F. Phys. Chem. Chem. Phys. 2007, 9, 3067. (c) Dunsch, L.;
Yang, S. F. Small 2007, 3, 1298. (d) Chaur, M. N.; Melin, F.; Ortiz, A. L.; Echegoyen, L. Angew. Chem., Int. Ed. 2009, 48, 7514.

(8) (a) Olmstead, M. M.; de Bettencourt-Dias, A.; Duchamp, J. C.; Stevenson, S.; Dorn, H. C.; Balch, A. L. J. Am. Chem. Soc. 2000, 122, 12220. (b) Dunsch, L.; Krause, M.; Noack, J.; Georgi, P. J. Phys. Chem. Solids 2004, 65, 309. (c) Yang, S. F.; Kalbac, M.; Popov, A.; Dunsch, L. ChemPhysChem 2006, 71990. (d) Yang, S. F.; Popov, A. A.; Kalbac, M.; Dunsch, L. Chem.-Eur. J. 2008, 14, 2084. (e) Chen, N.; Fan, L. Z.; Tan, K.; Shu, Y. Q. W. C. Y.; Lu, X.; Wang, C. R. J. Phys. Chem. C 2007, 111, 11823. (f) Yang, S.; Popov, A. A.; Chen, C.; Dunsch, L. J. Phys. Chem. C 2009, 113, 7616. (g) Stevenson, S.; Chancellor, C.; Lee, H. M.; Olmstead, M. H.; Balch, A. L. Inorg. Chem. 2008, 47, 1420. (h) Wang, X. L.; Zuo, T. M.; Olmstead, M. M.; Duchamp, J. C.; Glass, T. E.; Cromer, F.; Balch, A. L.; Dorn, H. C. J. Am. Chem. Soc. 2006, 128, 8884. (i) Yang, S.; Popov, A. A.; Dunsch, L. J. Phys. Chem. B 2007, 111, 13659. (j) Yang, S. F.; Popov, A. A.; Dunsch, L. Chem. Commun. 2008, 2885. (k) Chen, N.; Zhang, E. Y.; Wang, C. R. J. Phys. Chem. B 2006, 110, 13322. (l) Yang, S.; Popov, A. A.; Dunsch, L. Angew. Chem., Int. Ed. 2008, 47, 8196. (m) Yang, S.; Chen, C.; Popov, A.; Zhang, W.; Liu, F.; Dunsch, L. Chem. Commun. 2009, 6391.

(9) (a) Funasaka, H.; Sakurai, K.; Oda, Y.; Yamamoto, K.; Takahashi, T. Chem. Phys. Lett. 1995, 232, 273. (b) Huang, H. J.; Yang, S. H.; Zhang, X. X. J. Phys. Chem. B 2000, 104, 1473. (c) De Nadai, C.; Mirone, A.; Dhesi, S. S.; Bencok, P.; Brookes, N. B.; Marenne, I.; Rudolf, P.; Tagmatarchis, N.; Shinohara, H.; Dennis, T. J. S. Phys. Rev. B 2004, 69, 7. (d) Bondino, F.; Cepek, C.; Tagmatarchis, N.; Prato, M.; Shinohara, H.; Goldoni, A. J. Phys. Chem. B 2006, 110, 7289. (e) Kitaura, R.; Okimoto, H.; Shinohara, H.; Nakamura, T.; Osawa, H. Phys. Rev. B 2007, 76, 172409.

(10) (a) Wolf, M.; Müller, K.-H.; Skourski, Y.; Eckert, D.; Georgi, P.; Krause, M.; Dunsch, L. Angew. Chem., Int. Ed. 2005, 44, 3306. (b) Wolf, M.; Müller, K.-H.; Eckert, D.; Skourski, Y.; Georgi, P.; Marczak, R.; Krause, M.; Dunsch, L. J. Magn. Magn. Mater. 2005, 290, 290. (c) Zuo, T.; Olmstead, M. M.; Beavers, C. M.; Balch, A. L.; Wang, G.; Yee, G. T.; Shu, C.; Xu, L.; Elliott, B.; Echegoyen, L.; Duchamp, J. C.; Dorn, H. C. Inorg. Chem. 2008, 47, 5234. (d) Tiwari, A.; Dantelle, G.; Porfyrakis, K.; Watt, A. A. R.; Ardavan, A.; Briggs, G. A. D. Chem. Phys. Lett. 2008, 466, 155. (e) Smirnova, T. I.; Smirnov, A. I.; Chadwick, T. G.; Walker, K. L. Chem. Phys. Lett. 2008, 453, 233. (f) Chen, L.; Carpenter, E. E.; Hellberg, C. S.; Dorn, H. C.; Shultz, M.; Wernsdorfer, W.; Chiorescu, I. J. Appl. Phys. 2011, 109, 07B101.

(11) Treier, M.; Ruffieux, P.; Fasel, R.; Nolting, F.; Yang, S.; Dunsch, L.; Greber, T. Phys. Rev. B 2009, 80, 081403.

(12) (a) van der Laan, G.; Thole, B. T. Phys. Rev. B 1991, 43, 13401. (b) Stöhr, J. J. Magn. Magn. Mater. 1999, 200, 470. (c) Funk, T.; Deb, A.; George, S. J.; Wang, H.; Cramer, S. P. Coord. Chem. Rev. 2005, 249, 3.

(13) Piamonteze, C.; Flechsig, U.; Rusponi, S.; Dreiser, J.; Heidler, J.; Schmidt, M.; Wetter, R.; Schmidt, T.; Pruchova, H.; Krempasky, J.; Quitmann, C.; Brune, H.; Nolting, F. In preparation.

(14) (a) Thole, B. T.; Carra, P.; Sette, F.; Laan, G. v. d. Phys. Rev. Lett. 1992, 68, 1943. (b) Carra, P.; Thole, B. T.; Altarelli, M.; Wang, X. Phys. Rev. Lett. 1993, 70, 694. (c) Dreiser, J.; et al. Chem. Sci. 2012, 3, 1024.

(15) Ishikawa, N.; Sugita, M.; Wernsdorfer, W. Angew. Chem., Int. Ed. 2005, 44, 2931. 


\section{Supporting information on the communication "An endohedral single-molecule magnet with long relax- ation times: DySc ${ }_{2} \mathrm{~N} @ \mathrm{C}_{80}$ "}

\section{Synthesis of $\mathrm{DySc}_{2} \mathrm{~N} @ \mathrm{C}_{80}$}

The DySc ${ }_{2} \mathrm{~N} @ \mathrm{C}_{80}$ (isomer $\mathrm{I}_{h}$ ) was produced by a modified Krätschmer-Huffman dc-arc discharge method in a mixture of $\mathrm{NH}_{3}$ (20 mbar) and He (200 mbar) atmosphere as described elsewhere[1, 4]. Briefly, a mixture of naturally abundant $\mathrm{Dy}_{2} \mathrm{O}_{3}$ and $\mathrm{Sc}_{2} \mathrm{O}_{3}(99.9 \%$, MaTeck GmbH, Germany) with graphite powder was used (molar ratio Dy:Sc:C=1:1:15). After dc-arc discharge treatment, the soot was pre-extracted using acetone and further Soxhlet-extracted using $\mathrm{CS}_{2}$ for $20 \mathrm{~h}$. Fullerene isolation was performed by three-step HPLC. In the first step running in a HP instrument (series 1100) a combination of two analytical $4.6 \times 250 \mathrm{~mm}$ Buckyprep columns (Nacalai Tesque, Japan) was applied with toluene as the eluent. The second and third-step isolations were performed by recycling HPLC (Sunchrom, Germany) using a semi-preparative $4.6 \times 250 \mathrm{~mm}$ 5PYE or BuckyprepM column (Nacalai Tesque, Japan) and toluene as the eluent. An UV detector set to 320 $\mathrm{nm}$ was used for fullerene detection in all separations. The purity of the final samples was checked by laser desorption time-of-flight (LD-TOF) mass spectrometry both in positive and negative ion modes (Biflex III, Bruker, Germany). The DySc ${ }_{2} \mathrm{~N} @ \mathrm{C}_{80}$ compounds are characterized by UV-Vis-NIR and FTIR spectroscopy [3].

\section{X-ray absorption}

The x-ray absorption experiments were performed at the X-Treme beamline at the Swiss Light Source, Paul Scherrer Institut, Villigen, Switzerland, in fields up to $7 \mathrm{~T}$ along the beam direction and temperatures down to $2 \mathrm{~K}[2]$. The molecules were drop cast from a toluene solution onto a polycrystalline aluminum sample plate. The samples were cooled in zero field from room temperature down to $\sim 2 \mathrm{~K}$. The absorption was measured by recording the total electron yield normalized with the photon flux.

\section{SQUID}

The SQUID measurements were performed using undiluted samples (1) and a sample diluted with $\mathrm{C}_{60}(\mathbf{2})$. The net mass of the samples is in the $\mu \mathrm{g}$ range. The diluted sample was prepared by mixing two toluene solutions, one containing $\mathrm{C}_{60}$ and one containing DySc $_{2} \mathrm{~N} @ \mathrm{C}_{80}$, with volume ratio of 10:1. Taking into account the difference in solubility between the two molecules yields a final molar ratio between 10:1 and 20:1. To ensure a low background signal for the SQUID measurements, the molecules were drop cast onto a sample holder made from kapton foil with a mass of $\sim 10 \mathrm{mg}$. Before molecule deposition, the sample holders were characterized at different magnetic fields and temperatures. The sample holders for the present experiments exhibited a weak linear diamagnetic behavior. This diamagnetic background has been subtracted. The history of the samples is the 
same as for those used in the XMCD measurements, cooling from room temperature to 2 $\mathrm{K}$ took place in zero field. All magnetization versus field measurements were started at $+7 \mathrm{~T}$, and the magnetization loop was recorded within $\pm 7 \mathrm{~T}$ at an average field sweep rate of $1.3 \mathrm{mTs}^{-1}$.

\section{Full author list ref $14 \mathrm{c}$}

Jan Dreiser, Kasper S. Pedersen, Cinthia Piamonteze, Stefano Rusponi , Zaher Salman, Md. Ehesan Ali, Magnus Schau-Magnussen, Christian Aa. Thuesen, Stergios Piligkos, Hogni Weihe, Hannu Mutka, Oliver Waldmann, Peter Oppeneer, Jesper Bendix, Frithjof Nolting and Harald Brune.

\section{References}

[1] L. Dunsch, M. Krause, J. Noack, and P. Georgi, J. Phys. Chem. Solids 65 (2004), 309-315.

[2] C. Piamonteze, U. Flechsig, S. Rusponi, J. Dreiser, J. Heidler, M. Schmidt, R. Wetter, T. Schmidt, H. Pruchova, J. Krempasky, C. Quitmann, H. Brune, and F. Nolting, In preparation.

[3] S. Yang, A. A. Popov, C. Chen, and L. Dunsch, J. Phys. Chem. C 113 (2009), 76167623.

[4] S. Yang, A. A. Popov, and L. Dunsch, J. Phys. Chem. B 111 (2007), 13659-13663. 